\title{
Interferência da adição de fibras de polipropileno e finos de basalto na resistência mecânica de micro-concreto
}

\section{Interference from the addition of polypropylene fibers and thin basalt on mechanical strength of micro concrete}

\author{
André Meneghel Rando Junior ${ }^{1}$; Leonardo Guerra ${ }^{2}$; \\ Gilson Morales 3
}

\begin{abstract}
Resumo
Este estudo propõe adicionar resíduos de basalto e fibras de polipropileno ao micro-concreto observando sua resistência à tração e à compressão, bem como sua trabalhabilidade. Foi estabelecido inicialmente o traço de referência de concreto convencional 1:2:3 em massa, a relação água/cimento 0.47 e desenvolvidos traços com diferentes teores de adições. Foi fixada uma consistência padrão a partir do traço de referência, a qual foi mantida com o uso de aditivo plastificante. Verificou-se que os concretos com as adiçoes apresentaram-se mais untuosos e fáceis de manusear que o concreto de referência, mesmo com o mesmo abatimento. Ocorreu um aumento de 30\% na resistência mecânica à compressão comparado ao concreto convencional, que se considera ser pelo efeito filer do pó de basalto e um pouco pela interferência das fibras na progressão das fissuras térmicas. Não se verificou alteração considerável na resistência à tração. O estudo revelou que os materiais ensaiados são compatíveis em função do desempenho apresentado pelas misturas, tanto no estado fresco, quanto no estado endurecido. Pelos resultados mecânicos apresentados de resistência à tração e compressão concluiu-se que o uso desse material é viável para a produção de micro-concreto.
\end{abstract}

Palavras-chave: Concreto reforçado com fibras. Micro-concreto com fibras. Resíduo basáltico. Fibras de polipropileno.

\begin{abstract}
This study proposes to add basalt waste and polypropylene fibers in micro-concrete noting its tensile strength and compressive strength, as well as your workability. It was initially established the mix design of conventional concrete $1: 2: 3$, the water/cement ratio 0.47 and from this developed mix designs with diferent tax of additions. Default consistency was established from the mark, which was maintained with the use of additive plasticizer. It was found that the concretes with the additions were more unctuous and easy to handle that the reference concrete, even with the same slump. There was an increase of $30 \%$ of the compressive strength compared to conventional concrete, which are deemed to be at filer effect of basalt powder and a little by the interference of the fibers in the progression of thermal cracks. There was no significant change in tensile strength. The study revealed that the materials tested are compatible on the basis of the performance presented by the mixtures, both fresh, and in the hardened state.
\end{abstract}

Keywords: Fiber reinforced concrete. Micro concrete with fibers. Basaltic residue. Polypropylene fibers.

\footnotetext{
${ }^{1}$ Me. em Engenharia de Edificações e Saneamento, UEL, Londrina, Pr, Brasil; E-mail: jandrerandojr@hotmail.com

${ }^{2}$ Me. em Engenharia de Edificações e Saneamento, UEL, Londrina, Pr, Brasil; E-mail: leonardo.guerra@ @rtibagi.com.br

${ }^{3}$ Dr. Prof., Depto de Construção Civil, UEL, Londrina, Pr, Brasil; E-mail: gmorales@uel.br
} 


\section{Introdução}

O concreto reforçado com fibras (CRF) é um compósito de cimento Portland, constituído por agregados miúdos e graúdos, com a incorporação de fibras descontínuas. O emprego das fibras em concreto é uma prática já consolidada e data da década de 60, buscando-se, com a adição das fibras, controlar a incidência de fissuras, muito embora esta prática não garanta um concreto sem fissuras, uma vez que elas decorrem do calor liberado na hidratação do cimento.

Inicialmente foram usadas fibras de asbestos, ou amianto crisotila, misturadas ao cimento. Posteriormente, foram usadas outras fibras, como: fibras de aço, de polipropileno, de carbono, de vidro, de nylon, de celulose, acrílicas, de polietileno, de madeira, de sisal, entre outras, sendo as mais usadas, as fibras de aço e de polipropileno.

Este estudo propõe associar o efeito filer, de colmatação de vazios na microestrutura do concreto por meio da adição de finos de basalto, os quais, além de serem resíduos do processamento da rocha para a obtenção de agregados, ainda apresenta um grande potencial como material de construção. Como se trata de um material bastante fino, o seu emprego requer estudos a respeito da dosagem correta e das especificidades de adição para a obtenção de resultados favoráveis. Assim, o objetivo do trabalho refere-se a verificar o desempenho da associação dos materiais, fibras de polipropileno e finos de basalto, na produção do concreto.

\section{Revisão Bibliográfica}

\section{Uso de fibras em concreto}

O uso das fibras de aço se intensificou na década de 90 e continua muito frequente na execução de estruturas e, particularmente, na execução de pisos industriais, pavimentos rígidos e pistas de aeroportos, visando atenuar as manifestações patológicas causadas por efeitos mecânicos de abrasão, impacto e fadiga (AGOPYAN, 1993).

O uso das fibras se destina também a lajes em concreto, concretos projetados e pré-moldados, sendo que algumas dessas fibras apresentam módulo de elasticidade (E) maior que o do concreto. Dentre os usos mais frequentes, estão a execução de obras de maiores dimensões, como pontes, viadutos, concreto projetado, em especial para revestimento de túneis e contenção de taludes. As fibras, em função de suas características, podem conferir ao material, propriedades estruturais específicas, podendo ser utilizadas em peças estruturais que permitam redistribuição dos esfor- ços, mantendo-se a segurança e a integridade da estrutura e garantindo, dessa forma, maior durabilidade.

O concreto é um material compósito frágil, quebradiço, com baixa resistência mecânica à tração, da ordem de 1/10 de sua resistência à compressão e uma baixa capacidade de alongamento. Em decorrência disso, é normal que uma peça de concreto submetida a esforços de flexão, por exemplo, apresente fissuras na zona tracionada, motivo pelo qual se recorre à colocação de armadura de aço para suprir essa deficiência do material. O mesmo pode ocorrer quando o concreto é submetido à ação de agentes externos, como a infiltração de sulfatos, provocando a formação de etringita ou a ocorrência de corrosão da armadura, gerando expansões que provocam tensões às quais o concreto não consegue resistir.

A adição de fibras, pode transformar matrizes frágeis em materiais "quase dúcteis", como afirmam Bentur e Mindess (1990). As fibras, por serem descontínuas e se encontrarem distribuídas aleatoriamente no concreto, atravessam as fissuras, atribuindo ao concreto certa ductilidade após a fissuração. De maneira geral, pode-se afirmar que a adição de fibras ao concreto tem como objetivo controlar o seu comportamento pós-fissuração.

Fibras adequadamente aderidas à matriz cimentícia impedem a progressão das fissuras, bem como o seu alargamento, minimizando o efeito da fissuração. Em consequiência, o concreto passa a ter maior capacidade de absorver pequenas tensões de tração, com maior capacidade de deformação no estágio pós-fissuração. Em situações específicas, pode ocorrer um pequeno aumento da resistência à compressão. Desta forma, a presença das fibras produz os seguintes efeitos no concreto:

1. Contenção da propagação de fissuras na pasta de cimento endurecida;

2. Melhoria das propriedades dinâmicas do concreto;

3. Aumento da resistência do concreto à fadiga;

4. Melhoria do desempenho do concreto sujeito a cargas de impacto;

5. Aumento da ductilidade do concreto;

6. Aumento da coesão do concreto fresco;

7. Redução do efeito de cisalhamento;

8. Melhoria da aderência entre a matriz cimentícia e a armadura, após o início da fissuração;

9. Contenção do aumento das fissuras frente o alongamento das barras de aço; 
10. Redução da reflexão no concreto projetado;

11. Execução de camadas mais espessas no concreto projetado;

12. Aumento da resistência à tração na flexão, para elevados teores de fibras.

Segundo Mindess (1994), as fibras, por si só, têm pouco efeito nas propriedades mecânicas estáticas particularmente quando adicionadas em pequena quantidade. Teoricamente, a resistência à compressão do concreto não deveria aumentar além de $25 \%$ devido à adição de fibras. Porém, estudos com a adição de fibras de polipropileno têm revelado elevação da resistência mecânica à compressão.

Fibras de baixo módulo, como são as de polipropileno, reforçam a matriz cimentícia nas primeiras horas da hidratação, quando o módulo de elasticidade do concreto ainda apresenta baixos valores, segundo Figueiredo, Tanesi e Nince (2002). Conforme o módulo da matriz, o que justifica dizer que as fibras de polipropileno ou outras de baixo módulo de elasticidade são mais eficazes no reforço de argamassas do que de concretos, uma vez que essas fibras não conseguem garantir uma maior rigidez ao mesmo, impedindo que a fissuração prossiga.

Com a adição de fibras de polipropileno e finos de basalto, associa-se ao controle da propagação de fissuras o efeito filer, ou seja, o tamponamento dos micro poros, resultando em matrizes densas, melhorando o desempenho mecânico do concreto.

Uma outra questão a ser observada é a trabalhabilidade da mistura no estado fresco. De acordo com Bentur e Mindess (1990), a trabalhabilidade sofre alterações em função da presença de fibras, na razão direta à fração volumétrica e ao fator de forma das fibras.

Deste modo, o aditivo plastificante, segundo Góis (2010), melhora esta trabalhabilidade e garante uma melhor distribuição das fibras na mistura, cuidando-se para que este volume de aditivos não seja excessivo, trazendo como consequência uma elevação na porosidade e conseqüente redução da resistência mecânica.

\section{As fibras de polipropileno}

O polipropileno é um polímero hidrocarboneto sintético, cuja fibra é feita através de processos de extrusão e estiramento. São fibras quimicamente inertes e estáveis, não absorvem água, não se oxidam e resistem bem ao meio alcalino, já que o pH do concreto é de 12.6.
Estas fibras, em teores da ordem de $0.1 \%$ em volume, reduzem a retração plástica do concreto fresco, no período compreendido a cerca de 10 a 12 horas após a hidratação.

A forma e a orientação das cadeias poliméricas destas fibras, garantidas em grande parte pelo estiramento que acontece entre as temperaturas de transição vítrea e de fusão, durante o processo de fabricação das mesmas, atribui-lhes elevada resistência mecânica. Desta forma, sua tensão limite de ruptura é superior à do polímero bruto e seu alongamento máximo é menor (MINDESS; BENTUR, 2006).

Fibras de polipropileno garantem ainda o aumento da tenacidade de argamassas e concretos, uma vez que reforçam tridimensionalmente o compósito, interceptando as fissuras decorrentes da retração plástica ou hidráulica da pasta de cimento, além de proporcionarem maior resistência ao impacto, à abrasão e redução da permeabilidade.

Alguns trabalhos revelam que a resistência do concreto à ação do fogo pode ser melhorada com a adição de fibras de polipropileno. Estas, em função de temperaturas de fusão em torno de $165^{\circ} \mathrm{C}$, ao se fundirem criam pequenos vazios que permitem a dissipação da pressão de vapor, diminuindo as tensões.

De acordo com Cimolin \& Godinho (2015), as fibras de polipropileno melhoram a situação de exposição do concreto ao fogo porque, na ocorrência de lascamentos explosivos, essas fibras irão se decompor e gerar vazios no concreto, gerando caminhos para que o vapor proveniente do aumento da temperatura saia para o exterior da estrutura, evitando a ocorrência de mais lascamentos explosivos.

Segundo Figueiredo (2000), em decorrência do baixo módulo de elasticidade destas fibras, o ganho significativo de desempenho está associado às primeiras idades, quando o módulo de elasticidade do concreto também é baixo e as deformações estão associadas a um baixo nível de tensão, compatível com aquele absorvido pelas fibras de polipropileno.

\section{$O$ resíduo de britagem}

A obtenção de agregados por meio da cominuição de rochas basálticas, material particularmente abundante na Região Norte do Paraná, gera um certo volume de material sem destinação adequada na produção de concretos e argamassas. Em geral, estes resíduos são dispostos de forma inadequada, trazendo sérios danos ambientais, pois apresentam elevada finura e se depositam sobre a flora, trazem elevada turbidez aos cursos d'água, além de one- 
rar o setor produtivo com custos de transporte para sua remoção e disposição final.

Esta questão tem motivado o meio técnico à busca de adequação destes finos na produção de concretos.

O estudo dos perfis mineralógico e granulométrico dos resíduos de pedreira basáltica indica que este material apresenta um potencial bastante promissor no que diz respeito à produção de micro concretos, principalmente para uso em reparos de pavimentos rígidos. Filla (2011) indica que o basalto da região de Londrina, devido as suas características mineralógicas, é potencialmente sujeito à reação álcali-sílica. No entanto, afirma que, estando o material finamente moído, a elevação de sua superfície específica pode interferir como um agente inibidor da reação álcali-sílica, mesmo com o baixo resultado obtido para a atividade pozolânica deste material.

Guerra (2013) constatou a ocorrência de pontos de nucleação em cimentos com a adição de filer basáltico, possibilitando a elevação do teor de C-S-H na pasta de cimento.

Por outro lado, a adequação das faixas granulométricas dos agregados pode ser atingida com a incorporação de certo teor de finos de basaltos, melhorando as condições de empacotamento da mistura, o que permite a redução do teor de pasta de cimento no concreto.

\section{O Micro Concreto}

Os grandes avanços na tecnologia do concreto nas últimas décadas, o advento de novos materiais e a incorporação de adições, permitiram ganhos consideráveis na resistência mecânica, aumento da durabilidade e melhoria de outras propriedades do concreto.

Mehta e Monteiro (1994) denominam concretos de alto desempenho aqueles com resistência à compressão superior a $40 \mathrm{MPa}$ utilizando agregados convencionais. A ABNT NBR 8953:1992 classifica os concretos em dois grupos de resistência: os do grupo I, com resistência característica à compressão (fck) entre 10 e $50 \mathrm{MPa}$, e os do grupo II, com 55 a $90 \mathrm{MPa}$.

Um tipo particular deste grupo é o micro concreto, muito utilizado em reparos e recuperação de obras de arte. O desgaste sofrido na zona de integração entre a pista de rolamento e as obras de arte (pontes e viadutos) exige um material de reparo com alta resistência mecânica e pega rápida, de forma a se reduzir o tempo de limitação do tráfego.

O desempenho mecânico do concreto está associado a uma microestrutura densa e ao baixo índice de vazios. Fatores como o baixo índice de fissuras e o alto grau de empacotamento dos componentes interferem na permeabilidade do concreto e alteram sua estabilidade dimensional, melhorando seu desempenho em geral, elevando a resistência à abrasão e dificultando a ação de agentes deletérios, com conseqüente aumento da durabilidade.

A composição do micro concreto envolve o uso de agregados graúdos de dimensão máxima $9.5 \mathrm{~mm}$.

Estes agregados devem atender as especificações da norma de agregados para concreto ABNT NBR 7211 e apresentarem boa resistência à compressão, módulo de elasticidade maior ou igual ao da matriz cimentícia, forma cúbica e textura superficial que favoreça a aderência.

\section{Materiais e Método}

\section{Materiais}

Cimento: O aglomerante utilizado foi o cimento Portland de alta resistência inicial, CP V 32 - ARI, constituído por, aproximadamente, $95 \%$ de cimento puro (CP I), moído mais intensamente que os demais. Isto garante a obtenção de valores da resistência à compressão aos 7 dias correspondentes ao atingido pelos outros cimentos apenas aos 28 dias.

Agregados: A areia utilizada foi a quartzoza de rio, de graduação média, isenta de matéria orgânica, proveniente da Região Norte do Paraná. As características deste material são: Módulo de Finura 2.09; Dimensão Máxima $2.38 \mathrm{~mm}$; Massa Específica $2.64 \mathrm{~g} / \mathrm{cm}^{3}$ e Massa Unitária $1.58 \mathrm{~g} / \mathrm{cm}^{3}$. A brita utilizada, de origem do basalto, é classificada como brita 0, apresentando as seguintes características: Módulo de Finura 5.68; Dimensão Máxima 9.50mm; Massa Específica $2.90 \mathrm{~g} / \mathrm{cm}^{3}$ e Massa Unitária $1.62 \mathrm{~g} / \mathrm{cm}^{3}$.

Resíduo de Britagem: O resíduo de britagem utilizado apresenta elevada finura, com dimensões inferiores a $0.15 \mathrm{~mm}$, sendo proveniente dos britadores secundários e coletado por um sistema de filtros de manga. Este resíduo procede de pedreiras basálticas da região Norte do Estado do Paraná e se constituem num considerável passivo ambiental.

Aditivo Plastificante: Foi utilizado aditivo plastificante WRD 213 (Grace do Brasil), com densidade 1.19 $\mathrm{cm}^{3}$. Este aditivo, além de aumentar a fluidez do micro concreto, permite a redução da relação água/cimento. 
Método

Definição dos traços de concreto: Foram estudados dois traços de concreto a partir do traço unitário em massa padrão 1:2:3: um empregando fibras de polipropileno na proporção de $200 \mathrm{~g} / \mathrm{m}^{3}$ de micro concreto (4g de fibra/ $\mathrm{kg}$ de cimento). $\mathrm{O}$ consumo de fibras de polipropileno foi recomendação do fabricante, e teor de finos de basalto correspondente a $5 \%$ da massa do cimento (MIRF) e um traço de referência constituído por cimento, areia e brita 0 (MREF). Os concretos foram dosados segundo o traço unitário em massa 1:2:3, adotando-se uma relação água/aglomerante de 0.47 e teor de argamassa de $50 \%$. A consistência padrão obtida com o traço de referência foi mantida recorrendo-se ao emprego do aditivo plastificante WRD 213.

Caracterização dos materiais: Os materiais empregados foram caracterizados segundo os seguintes ensaios preconizados pela $\mathrm{ABNT}$ :

- Cimento: massa específica, massa unitária, finura (NBR 11579), tempo de pega (NBR NM 65);

- Areia: massa específica e massa unitária (NBR NM 52), análise granulométrica (NBR NM 248), inchamento (NBR 6467);

- Brita: massa específica e massa unitária (NBR NM 53), análise granulométrica (NBR NM 248), forma (NBR 7809), empacotamento;

- Resíduo de britagem: massa específica e massa unitária, análise granulométrica por sedimentação (Lei de Stokes).

Produção do concreto: Os materiais foram misturados em betoneira de eixo inclinado, com capacidade de 50 litros, adicionados na seguinte ordem: agregado graúdo e metade da água, misturados por dois minutos; agregado miúdo, seguido de mistura; cimento Portland e, por último, as fibras de polipropileno, os finos de basalto e o restante da água de amassamento contendo o aditivo diluído, no caso do concreto com adições. A betoneira permaneceu em funcionamento por 5 minutos, até a perfeita dispersão das fibras e obtenção de uma mistura homogênea. Em seguida, foi determinada a consistência do concreto recém misturado por meio do Ensaio de Abatimento (Slump Test).

Moldagem de corpos de prova: Para a elaboração dos trabalhos experimentais foram moldados seis corposde-prova cilíndricos, três na dimensão 100x200 mm e três na dimensão 150x300mm.
Os corpos de prova foram desmoldados após 24 horas e mantidos em câmara úmida até as datas das rupturas.

\section{Avaliação da resistência mecânica}

Para a avaliação da resistência à compreensão foi utilizada uma prensa marca EMIC com capacidade de até $2.000 \mathrm{KN}$ e foram usados corpos de prova cilíndricos, de dimensões 100x200mm, rompidos à idade de 7 dias. Para a avaliação da resistência à tração foram usados corpos de prova cilíndricos, de dimensões 150x300mm, rompidos por compressão diametral (Ensaio Brasileiro) (ABNT NBR 7222) aos 7 dias.

\section{Resultados}

A avaliação da incorporação das fibras ao concreto foi associada ao seu comportamento mecânico, uma vez que este reflete a maior ou menor incidência de fissuras na peça. Com relação às propriedades do concreto no estado fresco, os resultados do Ensaio de Abatimento indicaram constância de resultados, ao serem comparados com o concreto de referência, mantendo o abatimento na fasixa de $30 \mathrm{~mm}$. Por outro lado, mesmo com o slump muito próximo, registrou-se uma condição melhor de manuseio com o concreto com fibras, ou seja, a mistura se mostrou mais untuosa e menos resistente ao espalhamento. Nos ensaios de resistência à compressão, o concreto convencional (MREF) apresentou uma resistência média em torno de $30 \mathrm{MPa}$, enquanto o concreto com adição de fibras de polipropileno e finos de basalto (MIRF) apresentou uma resistência média da ordem de $42 \mathrm{MPa}$. Esse ganho de resistência, da ordem de $30 \%$ em relação ao concreto de referência, se deve ao efeito filer obtido pela adição de filer basáltico, o qual garante um melhor preenchimento dos poros, com um pequeno auxílio das fibras, muito embora a sua participação esteja mais associada à contenção das fissuras presentes, oriundas da liberação do calor de hidratação do cimento Portland.

Quanto à resistência à tração, não houve variação considerável, pois o concreto com adição de fibras (MIRF) apresentou 2.09 MPa e o concreto convencional (MREF) apresentou 2.04 $\mathrm{MPa}$, o que, estatisticamente pode ser considerada uma variação desprezível. Estes resultados são apresentados na Tabela 1.

\section{Conclusões}

Por meio dos resultados obtidos, conclui-se que a adição de fibras de polipropileno e de finos de basalto garan- 
Tabela 1 - Valores da resistência mecânica do micro concreto de referência (MREF) e do micro concreto com fibras (MIRF)

\begin{tabular}{ccc}
\hline Tipos de & \multicolumn{2}{c}{ Resistência } \\
\cline { 2 - 3 } Concreto & à Compressão & à Tração \\
\hline MREF & $30.00 \mathrm{MPa}$ & $2.04 \mathrm{MPa}$ \\
MIEF & $42.00 \mathrm{MPa}$ & $2.09 \mathrm{MPa}$ \\
\hline
\end{tabular}

Source: The authors.

tiram melhoria das propriedades mecânicas do concreto no tocante à resistência à compressão, trazendo benefícios ao sistema estrutural em que este micro concreto for empregado. Vale destacar que o uso das fibras não tem por objetivo aumentar a resistência do concreto à tração, muito embora o fenômeno possa ocorrer em função da contenção da expansão das fissuras de origem térmica.

Considera-se que este estudo traga avanços para a técnica de recuperação e manutenção de obras de arte e pavimentos rígidos, permitindo o desenvolvimento de traços de micro concreto com o nível de resistência requerido para estruturas sujeitas a elevadas solicitações e impactos.

A atenuação da expansão das microfissuras devido à presença das fibras pode contribuir indiretamente para o aumento da resistência à tração, muito embora não seja essa a razão principal de sua utilização. Esse desempenho conjunto das fibras e do filer calcário mostraram que os materiais apresentaram compatibilidade satisfatória, tanto no manuseio da mistura no estado fresco, na moldagem e amassamento dos corpos de prova, na integridade superficial observada na desmoldagem dos corpos de prova, na homogeneidade do concreto internamente ao corpo de prova e nos resultados obtidos pelos ensaios mecânicos realizados. De maneira geral, o micro concreto estudado apresentou um resultado satisfatório e pode ser utilizado seguramente para recuperação estrutural.

\section{Referências}

ASSOCIAÇÃO BRASILEIRA DE NORMAS TÉCNICAS. NBR 7809: Agregado graúdo - Determinação do índice de forma pelo método do paquímetro - Método de ensaio, São Paulo, 2019.

ASSOCIAÇÃO BRASILEIRA DE NORMAS TÉCNICAS. NBR 7222: Concreto e argamassa - Determinação da resistência à tração por compressão diametral de corpos de prova cilíndricos, São Paulo, 2011.
ASSOCIAÇÃO BRASILEIRA DE NORMAS TÉCNICAS. NBR 11579: Cimento Portland - Determinação do índice de finura por meio da peneira $75 \mu \mathrm{m}$ (n $\left.{ }^{\circ} 200\right)$, São Paulo, 2018.

ASSOCIAÇÃO BRASILEIRA DE NORMAS TÉCNICAS. NBR 6467: Agregados - Determinação do inchamento de agregado miúdo - Método de ensaio, Rio de Janeiro, 2009.

ASSOCIAÇÃO BRASILEIRA DE NORMAS TÉCNICAS. NBR 16607: 2018: Cimento Portland - Determinação dos tempos de pega, São Paulo, 2018.

\section{ASSOCIAÇÃO BRASILEIRA DE NORMAS TÉCNI-} CAS. NBR NM 52: Agregado miúdo - Determinação da massa específica e massa específica aparente, Rio de Janeiro, 2009.

ASSOCIAÇÃO BRASILEIRA DE NORMAS TÉCNICAS. NBR NM 53: Agregado graúdo - Determinação de massa específica, massa específica aparente e absorção de água, São Paulo, 2009.

ASSOCIAÇÃO BRASILEIRA DE NORMAS TÉCNICAS. NBR NR 248: Agregados - Determinação da composição granulométrica, Rio de Janeiro, 2003.

ASSOCIAÇÃO BRASILEIRA DE NORMAS TÉCNICAS. NBR 8953: Concretos para fins estruturais - Classificação pela massa específica, por grupos de resistência e consistência. Rio de Janeiro, 2015.

AGOPYAN, V. Emprego de materiais fibrosos na construção civil. In: SIMPÓSIO INTERNACIONAL SOBRE MATERIAIS

REFORÇADOS COM FIBRAS PARA CONSTRUÇÃO CIVIL, 199., 1993, São Paulo. Anais [...]. São Paulo: Epusp, 1993. p.11-25.

BENTUR, A.; MINDESS, S. Fibre reinforced cementitious composites. United Kingdom. Barking, Elsevier, 1990.

CIMOLIN, f. r. \& GODINHO, D. S. S. Estudo do efeito da fibra de polipropileno em concreto exposto a altas temperaturas. Artigo submetido ao Curso de Engenharia Civil da UNESC - como requisito parcial para obtenção do Título de Engenheiro Civil UNESC - Universidade do Extremo Sul Catarinense, 2015.

FILLA, J. C. Estudo da utilização de pó ultrafino de basalto como adição na preparação de um cimento mitigador da reação álcali-sílica. 2011. Dissertação (Mestrado Engenharia de Edificações e Saneamento) - Universidade Estadual de Londrina, Londrina, 2011. 
FIGUEIREDO, A. D. Concreto com fibras de aço. São Paulo: EPUSP, 2000. 69 p. (Boletim Técnico da Escola Politécnica da USP, Departamento de Engenharia de Construção Civil, BT/PCC/260).

FIGUEIREDO, A. D.; TANESI, J.; NINCE, A. A. Concreto com fibras de polipropileno (CFP). Téchne, São Paulo, v. 10, n. 66, p.48-51, 2002.

GÓIS, F. A. P. Avaliação experimental do comportamento de concreto fluido reforçado com fibras de aço. 2010. Dissertação (Mestrado em Engenharia Civil) - Universidade Federal de Alagoas, Maceió, 2010.

GUERRA, L. Viabilidade técnica da adição de finos de basalto na pasta de cimento Portland. Dissertação (Mestrado em Engenharia de Edificações e Saneamento) - Universidade Estadual de Londrina, Londrina, 2013.
MEHTA, P. K.; MONTEIRO, P. J. M. Concreto: estrutura, propriedades e materiais. São Paulo: Ed. PINI, 1994.

MINDESS, S. Fiber Reinforced Concrete: myth and reality advances in cement and concrete. ASME - American Society of Civil Engineers, 1994.

MINDESS, S.; BENTUR, A. Fibre reinforced cementitious composites. 2. ed. New York: Taylor \& Francis Group, Modern Concrete Technology Series, 2007. 
